\title{
An ARL1 mutation affected autophagic cell death in yeast, causing a defect in central vacuole formation
}

\author{
A Abudugupur ${ }^{1}, \mathrm{~K}_{\text {Mitsui }}{ }^{1}, \mathrm{~S}$ Yokota $^{2}$ and K Tsurugi, ${ }^{*, 1}$ \\ ${ }^{1}$ Department of Biochemistry 2, Yamanashi Medical University, Yamanashi/Japan \\ 2 Department of Biology, Yamanashi Medical University, Yamanashi/Japan \\ * Corresponding author: K Tsurugi, Department of Biochemistry 2, Yamanashi \\ Medical University, 1110 Shimokato, Tamaho, Nakakoma, Yamanashi \\ 409-3898, Japan. Tel/Fax: 055-273-6784; \\ E-mail: ktsurugi@res.yamanashi-med.ac.jp
}

Received 1.5.01; accepted 30.7.01

Edited by $\mathrm{H}$ Ichijo

\section{Abstract}

When the cdc28 strain of Saccharomyces cerevisiae is incubated at restrictive temperatures, the yeasts digest themselves in 7 days by activating autophagic machinery. In parallel, the cell-proliferative activity decreases progressively after about $48 \mathrm{~h}$. We have previously referred to this phenomenon as autophagic death. In the present study, we isolated and characterized a recessive mutant strain, dlp2, which delays the progression toward autophagic death. The cdc28 dlp2 cells contain many small vesicles instead of the large central vacuoles that are usually found in parental cdc28 cells. We showed that the dlp2 phenotype results from the presence of a single mutation in the gene ARL1 (ADPribosylation factor-like protein 1). Morphological and biochemical analyses of cdc28 dlp2 suggested that a defect in central vacuole formation is caused by aberrant membrane trafficking, although the protein-sorting to vacuoles is not affected. After a shift to a restrictive temperature, the components of the cytoplasm and nucleus of cdc28 dlp2 were condensed, with an accompanying formation of vesicles in the periphery (epiplasm) of the cells rather than an activation of the autophagic machinery. Introducing this ARL1 mutation into the normal ARL1 locus of the wild-type W303 strain again inhibited the progression of apoptotic cell death due to a defect in vacuole formation, which in this case was induced by the proapoptotic protein Bax. Thus, the ARL1 gene plays an important role in the formation of central vacuoles and in the progression of programmed cell death induced by cell-cycle arrest or Bax. These results suggested the presence of a programmed-cell death machinery in yeast that is similar to that related to the Type II cell death of mammalian cells characterized by autophagocytosis.

Cell Death and Differentiation(2002) 9,158-168. DOI: 10.1038/sj/ cdd/4400942

Keywords: autophagic death; Type II cell death; $A R L 1 ;$ dlp2; bax; central vacuole; membrane traffic; yeast

Abbreviations: ARL1, ADP-ribosylation factor-like protein 1; CDC, cell division cycle; sec, secretory; ARS, autonomously replicating sequence; EMS, ethylmethane sulfonate

\section{Introduction}

Programmed cell death or apoptosis is an active form of cell death essential for the development and homeostasis of multicellular organisms. However, in unicellular organisms like yeast, the expression of a number of proapoptotic mammalian genes like bax and p53 leads to cell death, and the cell death is inhibited by expression of mammalian antiapoptotic genes. ${ }^{1-5}$ Although the $S$. cerevisiae genome lacks structural homologues of the mammalian apoptosisrelated genes such as bax and caspase, these results suggest the presence in yeast of a cell death machinery that can be activated similarly by mammalian proapoptotic molecules. Along these lines, there have been some reports proposing the presence of a caspase-independent type of cell death called Type II cell death, ${ }^{6-9}$ which is another type of programmed cell death characterized by the early appearance of lysosomally derived, autophagic vacuoles leading to intense autophagocytosis. Xiang et al. ${ }^{10}$ reported that the expression of Bax in leukemic Jurkat cells induced a common pathway of apoptosis including the activation of caspase, but the addition of a caspase-specific inhibitor did not prevent Bax-induced cell death characterized by cytoplasmic vacuolation. However, in the yeast cells undergoing bax-induced cell death, morphological alterations suggestive of apoptosis, like chromatin condensation and the inward blebbing of the plasma membrane, have been reported. ${ }^{4,11,12}$

Previously, we found that, when temperature-sensitive, cell division cycle $(c d c)$ and secretory (sec) mutant cells were incubated at restrictive temperatures, they extensively degraded intracellular macromolecules like DNA, RNA and proteins in several days by activating the autophagic machinery. ${ }^{13}$ We suggested that this process was autophagic in nature depending on vacuolar proteinases, as the process was inhibited either in pep4 mutant cells which are deficient in the maturation of vacuolar proteinases or in cells treated with a proteinase inhibitor. ${ }^{13}$ Furthermore, we presented evidence showing that protein synthesis is required to promote the autophagic death, as death was delayed by cycloheximide and in protein synthesis mutants at the restrictive temperature. ${ }^{13}$ These results suggested the presence of programmed cell death in yeast. To search for genes involved in the autophagic death, we isolated mutants that exhibited delayed loss of proliferative activity (the Dlp phenotype) using cdc28 as a parental cell. We think that, if autophagic death is inhibited, the degradation of macromolecules involved in cell proliferation will be delayed. Three recessive mutants, named dlp1-3, showing the Dlp phenotype were isolated and, among these mutants, we previously characterized $d l p 11^{14}$ We found that the copy number of the endogenous $2 \mu$ plasmid of dlp1-I was 68-fold higher than that of the original cdc28, and that it decreased by half after the conversion to petite, which compensates the DIp phenotype, and lengthens the 
lifespan to some extent. Thus, we concluded that $D L P 1$ is a chromosomal gene that regulates the copy number of the $2 \mu$ plasmid. $^{14}$ The Dlp phenotypes are likely caused by the increased copy number of the endogenous $2 \mu$ plasmid containing an autonomously replicating sequence (ARS) element. $^{14}$ This conclusion is in agreement with the proposal of Sinclair and Guarente ${ }^{15}$ that the accumulation of any $A R S$ plasmids aside from extrachromosomal rRNA circles could shorten the lifespan of yeast. However, it is unlikely that the yet unidentified $D L P 1$ gene product participates directly in the progression of autophagic death.

In the present study, we characterized dlp2 and found that the Dlp phenotype of dlp2 was caused by a mutation in the gene $A R L 1$. The mutation caused a defect in central vacuole formation and delayed the progress of autophagic death in yeast. We further showed that $A R L 1$ participated in Bax-induced cell death in yeast, a finding which suggests that the $A R L 1$ gene plays an important role in the progression of programmed cell death via autophagocytosis induced by either cell-cycle arrest or Bax.

\section{Results}

\section{Phenotypes of the dlp2 cells}

The time-courses of the survival rates of $c d c 28$ dlp2 cells (the strains used in this report are listed in Table 1) after being transferred to the restrictive temperature showed that they had their loss of proliferative activity delayed by 2 days compared with the parental $c d c 28$ cells (Figure 1A). On the other hand, the cdc28 dlp2 cells grew at the same rate as the parental cells in the medium containing glucose (data not shown) and were resistant to nitrogen starvation, retaining their proliferation activity longer than 6 days, like the parental cells (Figure 1A). The reason that the mutant could survive nitrogen starvation, which requires activation of autophagocytosis, ${ }^{16}$ could be that the degradation of macromolecules is limited under nitrogen starvation, while in autophagic death it is massive and extensive. ${ }^{13}$ Morphologically, Nomarski images revealed that the cdc28 dlp2 cells grown at the permissive temperature $\left(25^{\circ} \mathrm{C}\right)$ lacked the central vacuoles that occupy a large part of the cytoplasm of the parental cells. Instead, their cytoplasm contained many small vesicles (Figure 1B). In addition, the cdc28 dlp2 cells appeared to be elongated compared to the parental cells. Vital staining of vacuoles with the fluorescent dye Lucifer yellow ${ }^{17}$ showed that the dye was taken up into multiple vesicular structures $0.5-1 \mu \mathrm{m}$ in diameter in cdc28 dlp2 cells, whereas it was taken up into central vacuoles (2$3 \mu \mathrm{m}$ in diameter) in the parental cdc28 cells (Figure 1B and Table 2). These results suggest that $c d c 28 d l p 2$ is deficient in the formation of central vacuoles.

\section{Isolation of a gene complementing the dlp2 mutant phenotype}

To isolate a gene complementing the Dlp phenotype of $c d c 28$ dlp2, we transformed $c d c 28$ dlp2 cells with a genomic library and isolated seven revertants. All of the genomic DNAs that were recovered from the revertants differed in length, and all were subsequently mapped on yeast chromosome II and were found to contain five genes in common, $A R L 1, U B S 1$, TYR1, 167C, and 168oW (Figure 2A). To determine which of these genes complemented the dlp2 mutation, we transformed cdc28 dlp2 cells with each gene and found that only cdc28 dlp2/YEp - ARL1 cells expressing ARL1, encoding a $20-\mathrm{kDa}$ GTP-binding protein, ${ }^{18}$ lost their proliferative activity within 4 days (Figure 2B). The time-course of the loss of proliferative activity of the cdc28 dlp2 transformed with $A R L 1$ in either multicopy (cdc28 dlp2/YEp - ARL1) or centromerebased plasmids ( $c d c 28$ dlp2/pRS - ARL1) showed that it lost the DIp phenotype and thus its proliferative activity within 3 days, even faster than the parental cdc28 ARL 1 cells (Figure $3)$. These results suggest that the DIp phenotype is suppressed by $A R L 1$ and that the dlp2 mutation may not be a simple loss-of-function type. It should be mentioned that the morphological observation by light microscopy showed that the delayed progression of autophagic death in dlp2 was rescued by the transformation with $A R L 1$ (data not shown).

Sequencing of the $A R L 1$ allele, referred to as arl1-1, from the cdc28 dlp2 cells revealed a point mutation of $A$ to $\mathrm{G}$ at nucleotide position 877 , with the first adenylate residue of the open reading frame of $A R L 1$ being nucleotide 1. This mutation is thought to cause an Asp to Gly substitution at amino acid position 151, which is located downstream from the GTP-binding domain. The cdc28 dlp2/ARL1, whose mutation site was replaced with the normal sequence, restored the DIp phenotype to that of the parental cells (Figure 3 ), indicating that the mutation in

Table 1 Genotypes of yeast strains used

\begin{tabular}{|c|c|}
\hline Strain & Parental strain and Genotype \\
\hline $185-3-4(c d c 28)^{a}$ & Mata cdc28-1 ade1 ade2 ura1 his7 lys2 tyr1 leu2 gal1 \\
\hline cdc28 dlp2 & 185-3-4, arl1-1 \\
\hline cdc28 dlp2/YEp-ARL1 & 185-3-4, arl1-1, YEp13M4-ARL1 \\
\hline$c d c 28$ dlp2/pRS-ARL1 & 185-3-4, arl1-1, pRS415-ARL1 \\
\hline cdc28 dlp2/ARL1 & 185-3-4, arl1-1 replaced with $A R L 1$ \\
\hline cdc28 arl1s & 185-3-4, ARL1::LEU2 \\
\hline cdc28 arl1 $\Delta / \mathrm{pRS}-\mathrm{arl1}-1$ & 185-3-4, ARL1::LEU2 pRSK103-art1-1 \\
\hline STX326-8B (cdc28) ${ }^{\mathrm{a}}$ & MAT $\alpha$ cdc28-1 ade1 lys2 met14 his7 tyr1 gal1 \\
\hline W303 & Mata ade2-1 his3-11 trp1-1 leu2-3 ura3-1 can1-100 \\
\hline W303/bax & W303, pYX223-bax \\
\hline W303/dlp2 & W303, arl1-1 \\
\hline W303/dlp2/bax & W303, arl1-1, pYX223-bax \\
\hline
\end{tabular}

${ }^{a}$ Obtained from Yeast Genetic Stock Center, University of California at Berkeley 
A

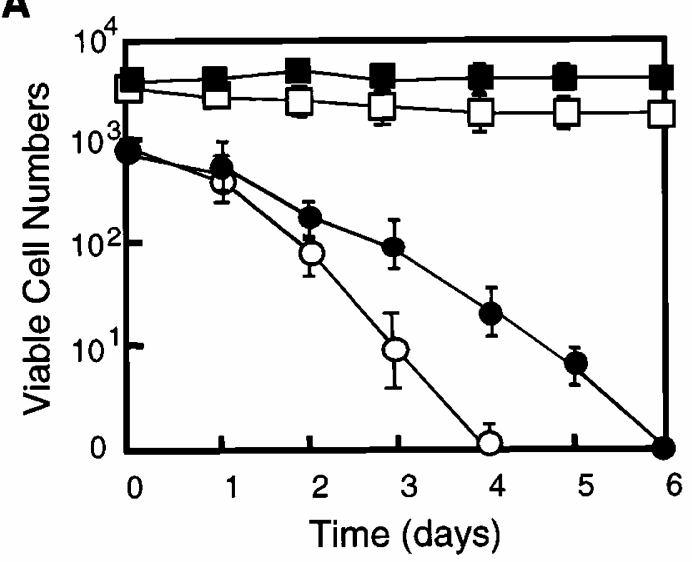

B

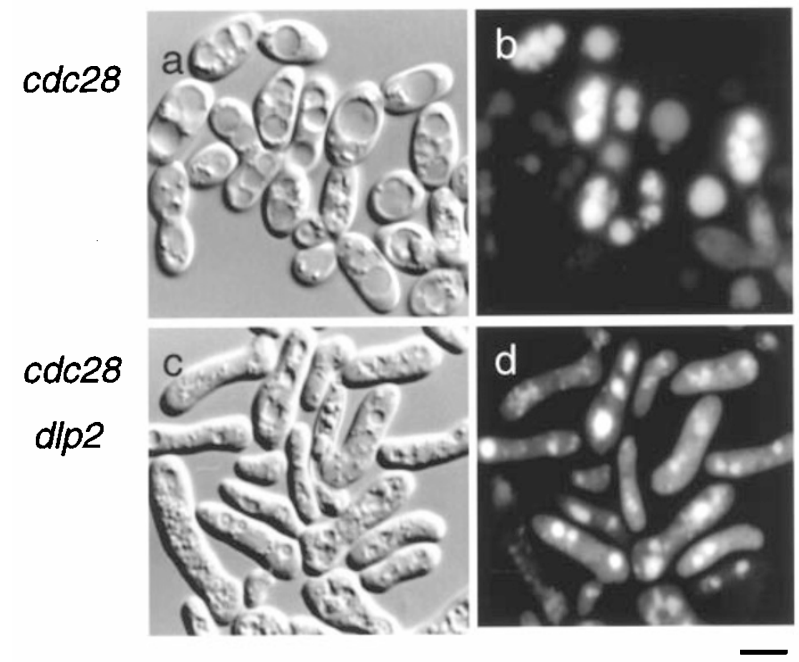

Figure 1 Some phenotypes of the cdc28 dlp2 cells. (A) Loss of proliferative activity of the parental $c d c 28(\bigcirc, \square)$ and derived-mutant $d / p 2(\mathbf{O}, \mathbf{\square})$ after transfer to the restrictive temperature $\left(38^{\circ} \mathrm{C}\right)(\mathrm{O}, \mathbf{0})$ and after transfer to the nitrogen-depleted medium and incubation at the permissive temperature $\left(28^{\circ} \mathrm{C}\right)(\square, \square)$. After incubation for the indicated periods, viable colonies were counted after incubation at $25^{\circ} \mathrm{C}$ for 3 days on YPAD medium plates. These are representative patterns of two independent experiments assayed in triplicate. (B) Light microscopic photographs of the parental cdc28 (a and $\mathbf{b}$ ) and $c d c 28$ dlp2 mutant (c and d) in the exponentially growing phase cultured at $25^{\circ} \mathrm{C}$. a and c, Nomarski images; b and d, vital staining with Lucifer yellow. Note that the cytoplasm of cells which heavily accumulated the dye in vacuoles was slightly stained probably due to a leaking of the dye

ARL1 causes the Dlp phenotype. Most cdc28 dlp2/ARL1 cells were found to contain central vacuoles, suggesting that the defect in central vacuole formation is also caused by the dlp2 mutation (data not shown).

\section{Morphological and biochemical phenotypes of $\operatorname{arl1\Delta }$}

To further examine whether the dlp2 phenotype is caused by the mutation of $A R L 1$, the phenotypes of the ARL1-deleted
Table 2 Morphology of dlp2 mutant cells. The parental cdc28 and derivedmutant cells grown at the permissive temperature $\left(25^{\circ} \mathrm{C}\right)$ were harvested in the exponentially growing phase and stained with Lucifer Yellow. Cells were classified into three groups depending on the vacuole morphology visualized with the dye. About 200 cells were examined

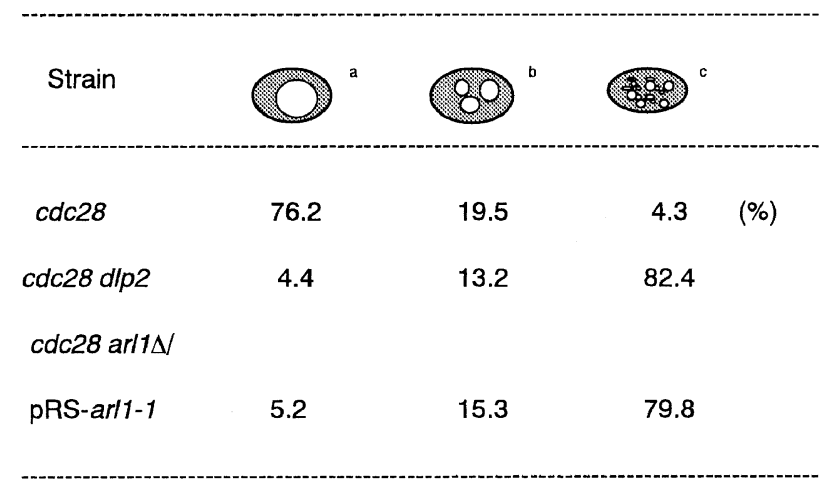

${ }^{a}$ Cells containing one or two central vacuoles. ${ }^{b}$ Cells containing small number of relatively large vesicles (an intermediate type). ${ }^{\circ}$ Cells containing many small vesicles instead of central vacuoles

mutant $c d c 28$ arl1 $1 \Delta$ were compared with those of $c d c 28$ dlp2 cells. Light microscopic observation showed that the large vacuoles are absent in most $c d c 28$ arl $1 \Delta$ cells (Figure $4 \mathrm{~A}$ ), as they are in cdc28 dlp2 cells (Figure 1B), and that the cell contours of $c d c 28$ arl1 $1 \Delta$ cells were elongated compared to those of wild-type cells, although they were shorter than those of $c d c 28$ dlp2 cells. In contrast, after the temperature shift, cdc28 arl1 $\Delta$ did not show an obvious Dlp phenotype, and lost its proliferative activity within 4 days (Figure $4 B$ ). However, that cdc28 arl14 showed higher proliferative activity than the parental cells by 3 days suggested that $c d c 28$ arl1 14 has a intermediate phenotype between that of the parental cdc28and cdc28 dlp2 cells. To account for this phenomenon, we considered the possibility that the dlp2 mutation disrupts the activity of a protein that compensates for the function of $A R L 1$. To address this possibility, we transformed $c d c 28$ arl1 $\Delta$ with recombinant plasmids harboring arl1-1. The transformant cdc28 arl14/pRS-arl1-1 showed the Dlp phenotype, retaining a much higher level of proliferative activity than the parental cells for the first 3 days of autophagic death, although it lost its proliferative activity rapidly thereafter (Figure 4B). The cdc28 arl14/pRS-arl1-1 was also found to lack central vacuoles (Figure 4A and Table 2). These results therefore suggest that the dlp2 mutation is not a loss-of-function type but instead a dominant-negative-like mutation. In contrast with the dominantnegative mutation, ${ }^{19}$ the arl1-1 product (the $A R L 1$ protein with the dlp2 mutation) did not disrupt the activity of the wild-type $A R L 1$ protein, as the dlp2 mutation is genetically recessive, but disrupts the activity of the protein that compensates for the function of $A R L 1$ in the $A R L 1$-deleted mutant.

\section{Morphological observation of the cdc28 dlp2 mutant by light microscopy at the restrictive temperature}

Cells were examined morphologically using vital staining of vacuoles with Luciferyellow (Figure 5). The parental cdc28cells accumulated autophagic body-like particles, which can be 
A

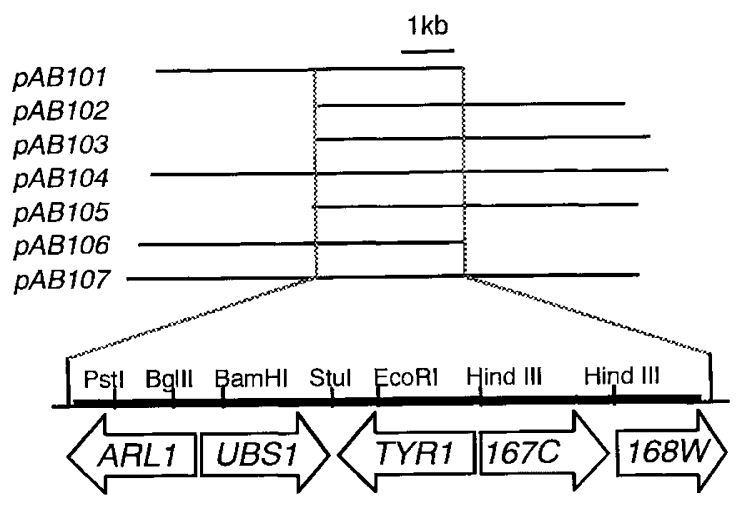

B

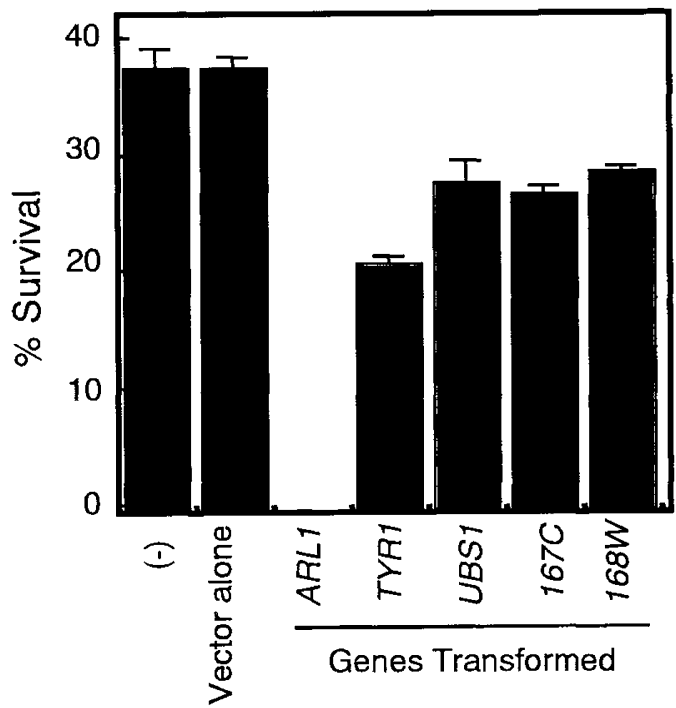

Figure 2 Search for the gene that complemented the DIp phenotype of $c d c 28$ dlp2. (A) Physical maps of DNA fragments obtained by the complementation study. (B) Survival rates of $c d c 28 d l p 2$ cells transformed with one of the five genes contained in the DNA fragments or vector alone. Viable colonies were counted after incubation at $38^{\circ} \mathrm{C}$ for 3 days followed by incubation at $25^{\circ} \mathrm{C}$ for 3 days

recognized as round shadows in the stained central vacuoles, $24 \mathrm{~h}$ after the shift to the restrictive temperature (Figure $5 \mathrm{~d}$, arrows). The presence of autophagic body-like particles has been shown by electron microscopic observation. ${ }^{13}$ The vacuoles were then fragmented into many vesicles during the next $24 \mathrm{~h}$ (Figure 5e, f). In contrast, the cdc28 dlp2 cells, which contained small vesicles instead of central vacuoles, did not show any significant changes by $48 \mathrm{~h}$ (Figure $5 \mathrm{i}-\mathrm{I}$ ). In addition, Nomarski images showed that the cytoplasm of $c d c 28$ dlp2 still contained many granules on day 7 , while that of parental $c d c 28$ cells became fragmented and shrunken due to extensive degradation of macromolecules on day 7 (data not shown).

\section{Electron-microscopic observation of the cdc28 dlp2 mutant}

Electron micrographs of yeast cells undergoing autophagic death (Figure 6) showed that the cdc28 dlp2 cells started

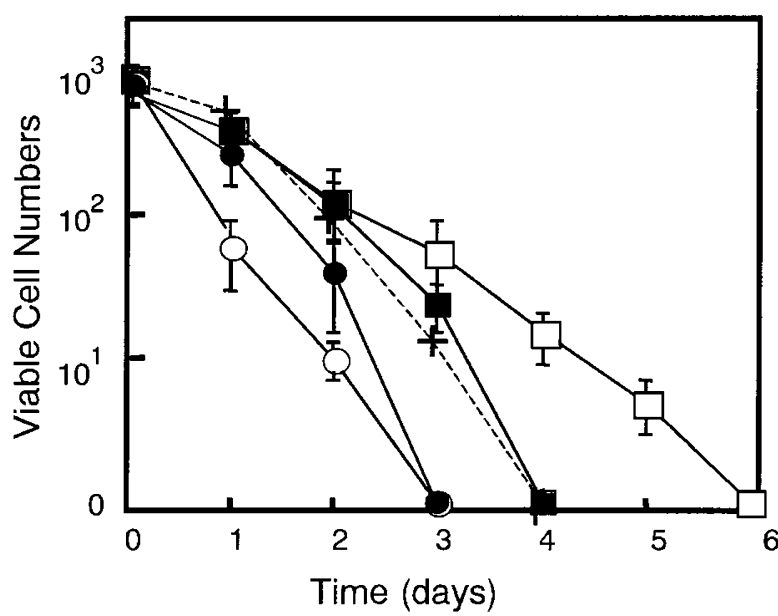

Figure 3 Loss of proliferative activity of $c d c 28 d l p 2$ mutant at the restrictive temperature $\left(38^{\circ} \mathrm{C}\right)$ after transformation with $A R L 1 . c d c 28$ dlp2 transformed with YEp13M4-ARL1 (cdc28 dlp2/YEp-ARL1, O), pRS415-ARL1 (cdc28 dlp2/pRS - ARL1, $)$, the vector YEp 13M4 alone ( $\square$ ), or cdc28 dlp2 in which the point mutation was replaced with the wild-type $A R L 1$ sequence (cdc28 dlp2/ARL1, $\mathbf{\text { ) }}$ were grown at $38^{\circ} \mathrm{C}$ in YPAD for the indicated periods, and viable colonies were counted after incubation at $25^{\circ} \mathrm{C}$ for 3 days on YPAD medium plates. Loss of proliferative activity of the parental $c d c 28(+)$ is shown as a control. These are representative patterns of two independent experiments assayed in triplicate

a proliferation of the cytoplasmic membrane $24 \mathrm{~h}$ after the temperature up-shift, as the parental cdc28 cells had (Figure $6 \mathrm{~b}, \mathrm{f}$ ). The result suggested that the dlp2 mutation did not affect the autophagosome formation found at around $24 \mathrm{~h}$ of the autophagic death. ${ }^{13}$ However, the cdc28 dlp2 cells accumulated abundant electron-dense granules in both the cytoplasm and nucleus at $48 \mathrm{~h}$ (Figure 6g, h). In contrast, there were either large vacuoles containing autophagic body-like particles ${ }^{13,16}$ or a large number of vacuolar vesicles in the parental cells, probably resulting from fragmentation of the central vacuoles $48 \mathrm{~h}$ after the temperature up-shift (Figures 6c, d). It should be mentioned that the autophagic bodies accumulated in the vacuoles in the absence of protease inhibitor, in contrast to their behavior under nitrogen starvation in which they accumulated in the presence of proteinase inhibitor PMSF, or in mutant cells lacking vacuolar proteinases and peptidases, or in wild-type cells. ${ }^{16}$ This result supported the notion that the degradation of macromolecules in autophagic death was much more extensive than that under nitrogen starvation. In addition, most $c d c 28$ dlp2 cells had multiple small vesicles in the epiplasm, the space between the cell membrane and cell wall (Figure $6 \mathrm{~g}, \mathrm{~h}$, arrows). The epiplasmic vesicles were sometimes observed in the parental cdc28 cells undergoing autophagic death (Figure 6d, arrowheads), but they were markedly increased in size and number in cdc28 dlp2 cells (Table 3 ). Thus, the morphological observations made by electron microscopy suggested that cdc28 dlp2 cells, which had a defect in central vacuole formation, condensed the components of the cytoplasm and nucleus, with an accompanying formation of epiplasmic vesicles. 
A

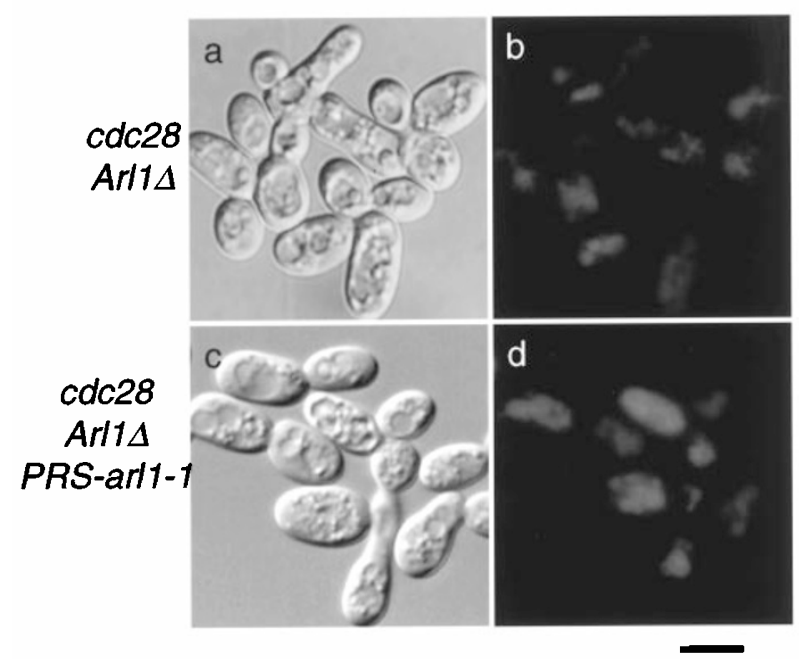

B

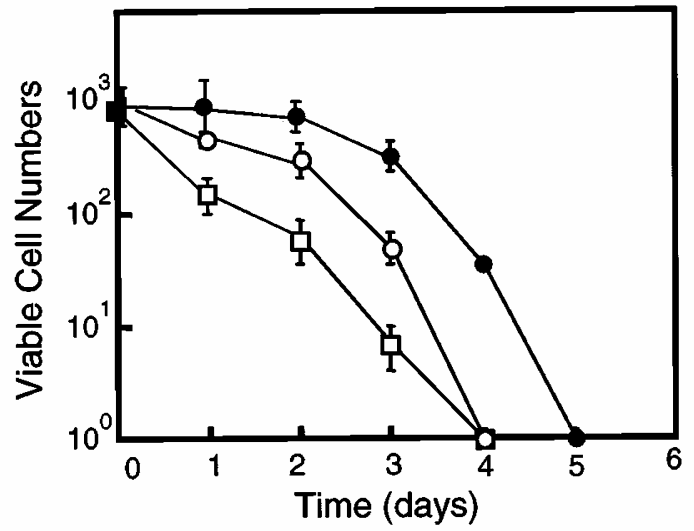

Figure 4 Effect of arl1-1 expression on the phenotype of $c d c 28$ arl1 $\Delta$ cells. (A) Light microscopic photographs of $c d c 28$ arl1 $(\mathrm{a}$ and b) and $c d c 28$ arl1 $\Delta /$ pRS-arl1-1 (c and d) in the exponentially growing phase cultured at $25^{\circ} \mathrm{C}$. a and c, Nomarski images; b and d, vital staining with Lucifer yellow. (B) Loss of proliferative activity of $c d c 28$ arl1s $(O)$ and $c d c 28$ arl1s transformed with pRSK103-arl1-1 (cdc28 arl1s/pRS-arl1-1, @) after transfer to the restrictive temperature $\left(38^{\circ} \mathrm{C}\right)$. Proliferation activity of the parental $c d c 28$ cells $(\square)$ as a control (these data were also shown in Figure 1). After incubation for the indicated periods, viable colonies were counted after incubation at $25^{\circ} \mathrm{C}$ for 3 days on YPAD medium plates. These are representative patterns from assays performed in triplicate

\section{Membrane and protein transport to vacuoles in cdc28 dlp2 cells}

To investigate some biochemical basis for the defect in central vacuole formation in cdc28 dlp2 cells, we first examined whether the cdc28 dlp2 cells have any defects in terms of protein-sorting into vacuoles. For this purpose, we determined the distributions of the precursors and mature forms of the soluble vacuolar carboxypeptidase $\mathrm{Y}$ and membrane-bound vacuolar alkaline phosphatase by Western blotting (Figure 7), as these proteins are known to be processed into their mature forms in vacuoles. ${ }^{20,21}$ The distribution patterns of these proteins were essentially the same in the parental and mutant cells, which indicates that protein-sorting into vacuoles was not impaired in cdc28 dlp2 cells. The results also suggested that the small vesicles found in cdc28 dlp2 cells are mature vacuoles and not prevacuolar compartments where the vacuolar proteins are not processed into mature forms. ${ }^{22,23}$ Then, to examine whether membrane metabolism of vacuoles was affected, the lipophilic fluorescent dye FM4-64, which has been used to follow bulk membrane-trafficking in yeast, ${ }^{24}$ was used (Figure 8). In the parental cells, vacuolar membranes were well stained $30 \mathrm{~min}$ after the addition of the dye, in agreement with a previous report, ${ }^{24}$ and the dye began to fade out of the vacuolar membranes after $2 \mathrm{~h}$ (Figures $8 \mathrm{~d}, \mathrm{f}$ ). In contrast, in the cdc28 dlp2 cells, small vesicles were stained strongly in $30 \mathrm{~min}$ and the dye remained or even continued to accumulate in the vesicles at $2 \mathrm{~h}$ (Figures $8 \mathrm{j}, \mathrm{l}$ ). Thus, it is likely that the dlp2 mutation affected membrane trafficking but not protein transport, resulting in a defect in the formation of the central vacuoles. It should be added that the dye did not reach the vacuolar membranes within $15 \mathrm{~min}$ in the parental or mutant cells (data not shown). This finding suggests that the incorporation rate of membranes into the vacuoles was not affected as much in the mutant cells compared to the parental cells.

\section{Role of ARL1 in Bax-induced cell death in yeast}

It has recently been postulated that the mammalian proapoptotic protein Bax induces a type of cell death in yeast that exhibits some morphological features of apoptosis in higher organisms. ${ }^{1-5}$ To investigate whether $A R L 1$ participates in the process of Bax-induced apoptosis as well as that of autophagic death in yeast, we employed the strain W303 for transformation with the galactose-inducible bax gene. We did not use parental cdc28 cells in this part of the study because they do not grow on galactose medium. The introduction of the dlp2 mutation into the $A R L 1$ locus of W303 (W303/dlp2) significantly decreased the proportion of cells having typical central vacuoles (Figures 9a, c and Table 4). However, about $70 \%$ of the W303/dlp2 cells showed the faint contours of a central vacuole overlapping multiple vesicles stained with Lucifer yellow, which suggested that the effect of the dlp2 mutation was relatively weaker in W303 than in the parental cdc28 cells. After Bax was induced on galactose medium, at most about $80 \%$ of the W303/bax cells lost viability within $24 \mathrm{~h}$, reaching a plateau thereafter, while W303 cells carrying arl1-1 (W303/dlp2/bax) were resistant to Bax-induced cell death (Figure 10A). This result suggests that the mutation of $A R L 1$ inhibits the promotion of programmed cell death that is induced by Bax in yeast.

\section{Morphological observation of yeast undergoing Bax-induced cell death}

Nomarski images showed that, after Bax induction, the cytoplasm of most W303/bax cells was shrunken, like that of the parental cdc28 cells undergoing autophagic death, while W303/dlp2/bax cells did not show any significant change (Figure 9). The electron micrographs revealed that $24 \mathrm{~h}$ after Bax induction, some W303/bax cells showed thin, 

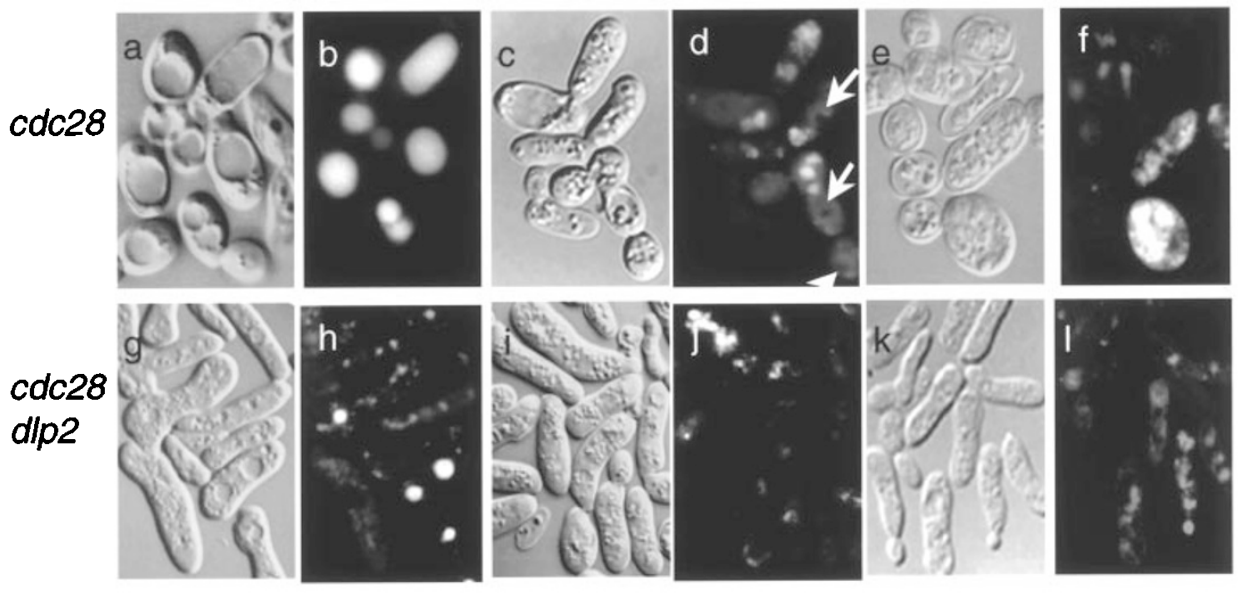

Figure 5 Light microscopic photographs of the parental $c d c 28(\mathbf{a}-\mathbf{f})$ and mutant $c d c 28$ dlp2 cells $(\mathbf{g}-\mathbf{l})$ after transfer to the restrictive temperature. Photographs were taken 0 (a, b, g and h), 24 (c, d, i and j) and $48 \mathrm{~h}(\mathbf{e}, \mathbf{f}, \mathbf{k}$ and $\mathbf{I})$ after the temperature shift. a, $\mathbf{c}, \mathbf{e}, \mathbf{g}, \mathbf{i}$, and $\mathbf{k}$, Nomarski images; b, d, f, h, j, and I, vital staining with Lucifer yellow. Arrows in $\mathbf{d}$ indicate autophagic body-like structures. The bar represents $1 \mu \mathrm{m}$

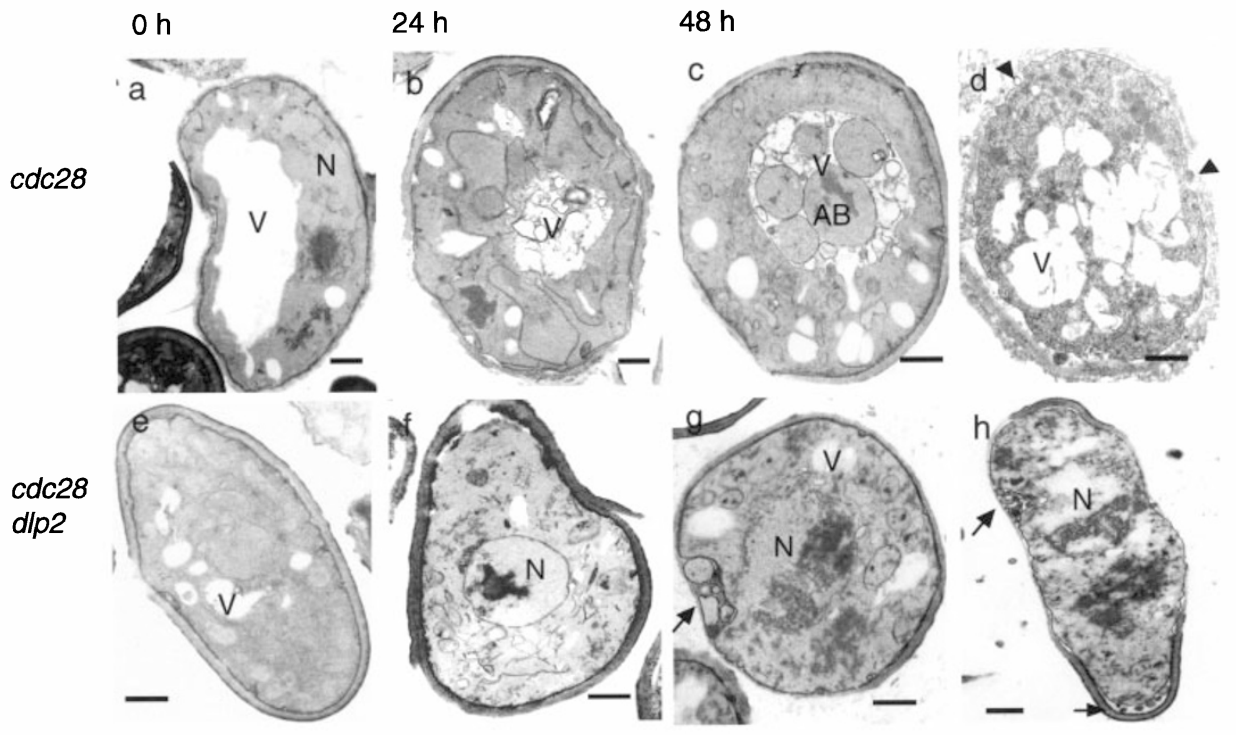

Figure 6 Electron micrographs of representative $c d c 28(\mathbf{a}-\mathbf{d})$ and $c d c 28 d l p 2(\mathbf{e}-\mathbf{h})$ cells after the shift to the restrictive temperature. Photographs were taken 0 (a and $\mathbf{e}), 24$ (b and f) and 48 (c, d, $\mathbf{g}$ and $\mathbf{h}$ ) hours after the temperature shift. Arrows and arrowheads indicate epiplasmic vesicles. Abbreviations are: N, nucleus; $\mathrm{V}$, vacuole; $\mathrm{AB}$, autophagic body-like vesicle. The bar represents $1 \mu \mathrm{m}$

Table 3 Accumulation of epiplasmic vesicles in dlp2 mutant cells during the autophagic death. Electron micrographs of yeast cells undergoing autophagic death were examined whether the cells contain epiplasmic vesicles. The cells whose cell walls were stripped by partial digestion with zymolyase at fixation ${ }^{13}$ were eliminated from the analysis. They were classified into four groups depending on the number of epiplasmic vesicles visible

\begin{tabular}{lcccc}
\hline No. of vesicles & $\mathbf{0}$ & $\mathbf{1} \sim \mathbf{3}$ & $\mathbf{4} \sim \mathbf{1 0}$ & $>\mathbf{1 1}$ \\
\hline cdc28 $(16)^{\mathrm{a}}$ & 9 & 5 & 2 & 0 \\
${\text { cdc28 dlp2 }(7)^{\mathrm{a}}}^{\mathrm{c}}$ & 1 & 1 & $4(2)^{\mathrm{b}}$ & $1(1)^{\mathrm{b}}$ \\
\hline
\end{tabular}

${ }^{\mathrm{a}}$ Total cell numbers examined. ${ }^{\mathrm{b}}$ Number of cells that contain epiplasmic vesicles larger than $0.5 \mu \mathrm{m}$ in diameter fragmented cytoplasm similar to that of cells in the final stage of autophagic death, ${ }^{13}$ whereas other cells still contained thick cytoplasm with large vacuoles (Figure 10B). In contrast, almost all of the W303/dlp2/bax cells contained thick cytoplasm with electron-dense granules (similar to those found in cdc28 dlp2 cells as shown in Figures 6e, f) sparsely distributed in the cytoplasm and/or vacuoles (Figure 10B). The morphological changes induced by Bax were similar to those found during autophagic death, although the extent of the changes was smaller. 


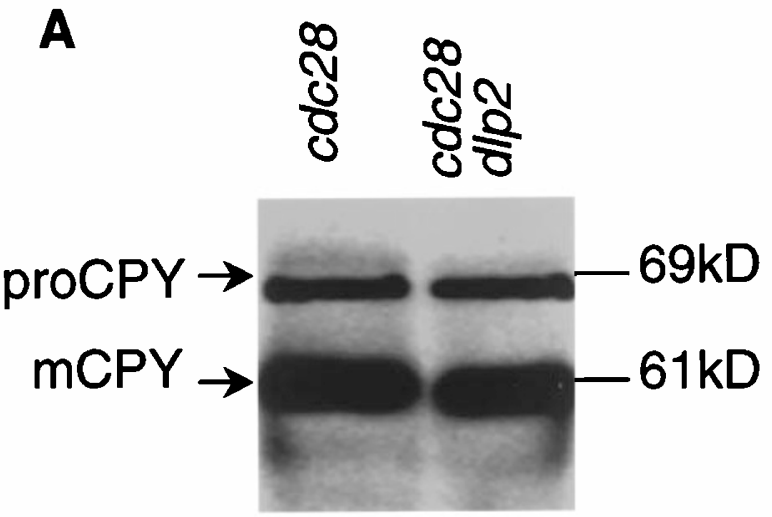

\section{Discussion}

ADP-ribosylation factors (ARFs) and ADP-ribosylation factorlike proteins form a family of highly conserved, approximately $20 \mathrm{kDa}$ guanine nucleotide-binding proteins. ${ }^{25,26}$ Based on their intracellular locations and on the biochemical characteristics of various mutants, they are thought to participate in vesicular transport in both exocytic and endocytic pathways. $^{25,26}$ In yeast, five members of the family have been reported. ${ }^{27}$ Among them, ARF1 and ARF2 have been best characterized functionally, together with their GTPaseactivating factors, ${ }^{28-30}$ and are thought to act in vesicular transport from the Golgi apparatus to the endoplasmic reticulum. $A R L 1$ of yeast was purified by Lee et al. ${ }^{18}$ and shown to be dispensable for cell viability, and to be located in the cytosol as well as in the Golgi apparatus.

We have shown in this report that the dlp2 mutation of $A R L 1$ caused a defect in central vacuole formation that

B

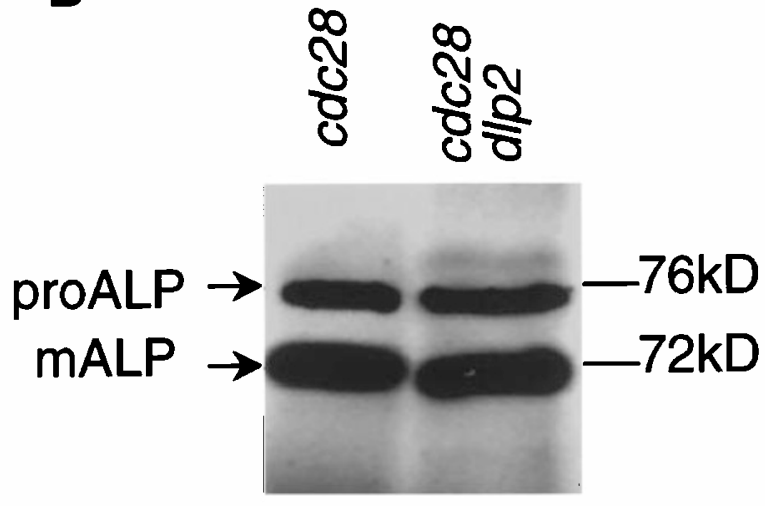

Figure 7 Protein sorting to vacuoles in $c d c 28$ dlp2 cells. Distributions of precursors (pro) and mature forms $(\mathrm{m})$ of $(\mathbf{A})$ carboxypeptidase $\mathrm{Y}(\mathrm{CPY})$ and (B) alkaline phosphatase (ALP) in cell lysates from the parental cdc28 and cdc28 dlp2 cells were determined by Western blotting
Table 4 Morphology of dlp2 mutant of the strain W303. The parental 303 and mutant W303/dlp2 grown at $30^{\circ} \mathrm{C}$ on glucose were harvested in the exponentially growing phase and stained with Lucifer Yellow. Cells were classified into three groups depending on the vacuole morphology. About 200 cells were examined

$\begin{array}{llllll}\text { Strain } & & & \\ \text { W303 } & 20.2 & 4.2 & 2.3 & (\%) \\ \text { W303/dlp2 } & & & & \\ \end{array}$

${ }^{a}$ Cells containing one or two central vacuoles. ${ }^{b}$ Cells containing a faint contour of central vacuoles overlapping many small vesicles. ${ }^{\mathrm{C}}$ Cells containing many small vesicles instead of central vacuoles. ${ }^{\mathrm{d} C e l l s}$ containing shrunk cytoplasm stained strongly with the dye. These supposed to be dying

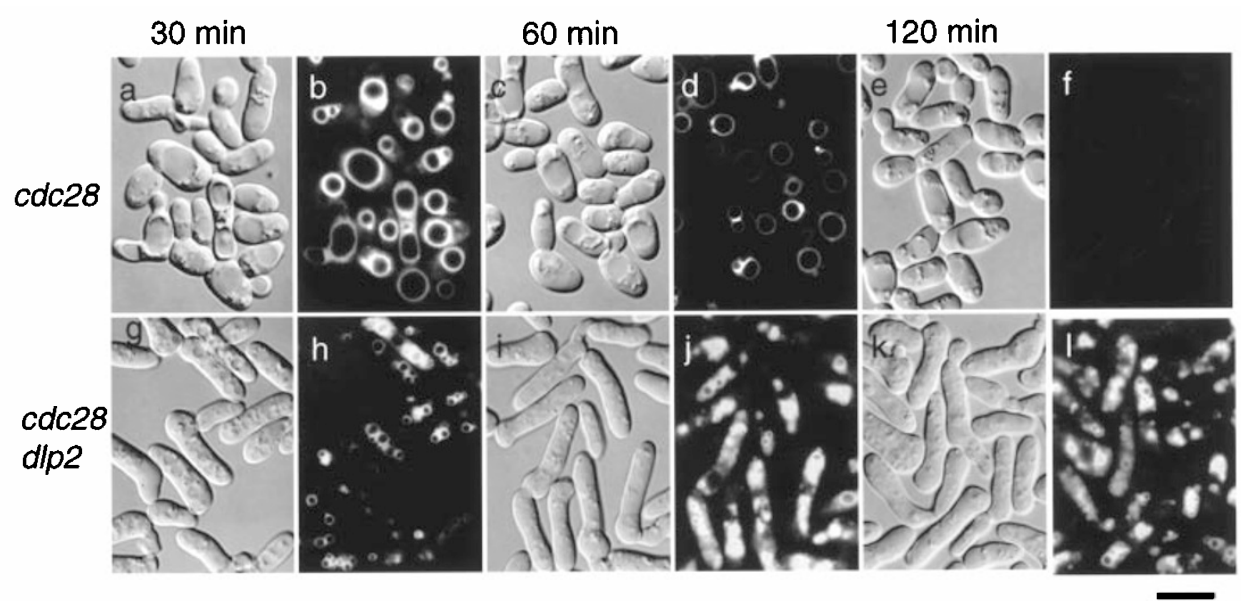

Figure 8 Membrane trafficking to vacuoles in the parental cdc28 $(\mathbf{a}-\mathbf{f})$ and mutant $c d c 28$ dlp2 cells $(\mathbf{g}-\mathbf{l})$. Light microscopic photographs were taken 30 (a, b, $\mathbf{g}$ and $\mathbf{~ h}$ ), 60 (c, d, i and j), and 120 min (e, f, $\mathbf{k}$ and $\mathbf{~ I ) ~ a f t e r ~ t h e ~ a d d i t i o n ~ o f ~ t h e ~ l i p o p h i l i c ~ s t y r y l ~ d y e ~ F M ~} 4-64$ at $4 \mu \mathrm{M}$. a, c, e, g, i, and k, Nomarski images; b, d, f, h, j, and I, vital staining with FM 4-64 

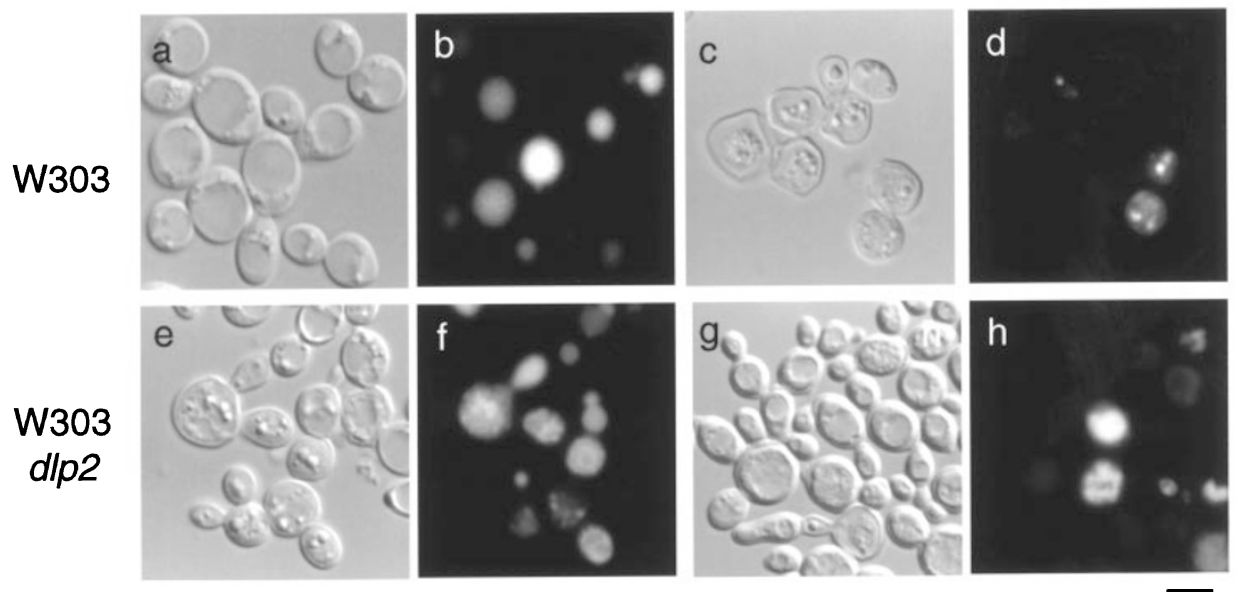

Figure 9 Light microscopic photographs of W303/bax $(\mathbf{a}-\mathbf{d})$ and mutant W303/dlp2/bax cells $(\mathbf{e}-\mathbf{h})$ after Bax induction on galactose medium. Photographs were taken 0 (a, b, e and f), and 24 (c, d, $\mathbf{g}$ and $\mathbf{h}$ ) $\mathbf{h}$ after the Bax induction. $\mathbf{a}, \mathbf{c}, \mathbf{e}$, and $\mathbf{g}$, Nomarski images; $\mathbf{b}, \mathbf{d}, \mathbf{f}$, and $\mathbf{~ h , ~ v i t a l ~ s t a i n i n g ~ w i t h ~ L u c i f e r ~ y e l l o w . ~ T h e ~ b a r ~}$ represents $1 \mu \mathrm{m}$

resulted in a delay in the loss of proliferation activity and in the progress of autophagic death. Although the DIp phenotype of dlp2 is associated with the delayed progression of autophagic death, we do not think that the Dlp phenotype can be specifically linked to autophagic death. We used the DIp phenotype as a selective marker to search for mutants affected in the autophagic death on the basis of the idea that the delay of autophagocytosis will in turn delay the degradation of proliferation-related machinery. We have also shown that the defect in central vacuole formation is probably due to aberrant membrane trafficking. In this respect, it should be noted that the CIN4 gene of the yeast $S$. cerevisiae, whose mutation caused chromosome instability by affecting microtubule stability, ${ }^{31}$ was identified as the yeast homologue of mammalian ADP-ribosylation factor-like protein Arl2. ${ }^{32}$ As it is now recognized that microtubules are involved in the motility of various organelles via membrane trafficking, ${ }^{33}$ we suspect that $A R L 1$ and other related proteins may also be involved in microtubule-based membrane trafficking or related reactions, although the precise mechanism remains to be clarified.

In this study, we showed that central vacuoles play an important role in the promotion of programmed cell death induced by either cell cycle arrest or the proapoptotic protein Bax. Yeast cells undergo programmed cell death by digesting themselves in vacuoles rather than by condensing themselves into apoptotic bodies, as occurs in metazoan apoptosis. Although morphological alterations that are suggestive of apoptosis like chromatin condensation and the inward blebbing of the plasma membrane could be seen in the wild-type cells undergoing autophagic death (Figure 8) or apoptosis, ${ }^{4,11,12}$ they were observed to be augmented in the cells carrying the mutant $A R L 1$ (arl1-1). This augmentation was accompanied by the formation of epiplasmic vesicles that were suggestive of the apoptotic bodies found in metazoan apoptosis. This result suggested that yeast cells are primarily programmed to kill themselves by autophagocytosis. The morphological features found in programmed cell death of yeast are similar to those of 'Type II physiological cell death'. ${ }^{6-9}$ The preferential activation of autophagocytosis in yeast cell death is probably due to the presence of a thick cell wall, which would prevent apoptotic bodies from undergoing heterophagocytosis by live cells. This conclusion implies that a basic function of apoptosis in yeast is the supplying of nutritional compounds from the dying cells, by the dying cells, for the live cells. The fact that the $S$. cerevisiae genome lacks structural homologues of caspases and that its programmed cell death is characterized by autophagocytosis suggests the presence of a caspaseindependent cell death machinery that can be induced by either Bax or cell cycle arrest at the restrictive temperature.

To elucidate the molecules involved in the mechanism of autophagy under nitrogen starvation conditions, Ohsumi and co-investigators used a genetic approach. A total of 16 autophagy-deficient mutants (apg) were isolated in this study. ${ }^{34}$ Among these mutants, a protein conjugation system in which Apg12p is covalently bonded to Apg5p via an isopeptide bond was found to be essential for autophagy. ${ }^{35}$ Furthermore, these researchers found that the conjugation of Apg1p and Apg13p is required for autophagy induction, and that the binding affinity of Apg13p to Apg1p is reduced by hyperphosphorylation by Tor protein, a phosphatidylinositol kinase-related kinase. ${ }^{36}$ In this study, we eliminated the apg mutants sensitive to nitrogen starvation ${ }^{34}$ during the course of the screening of dlp mutants, ${ }^{14}$ and thus it remains to be clarified whether APG genes are involved in autophagic death. We are now investigating whether the conjugation systems are also required for autophagic death.

\section{Materials and Methods}

\section{Yeast strains and media}

The strains of $S$. cerevisiae used in this study are listed in Table 1 . The strain 185-3-4 carrying cdc28, from which various mutants were derived, is referred to thereafter as the parental $c d c 28$ cells. Cells were 
A

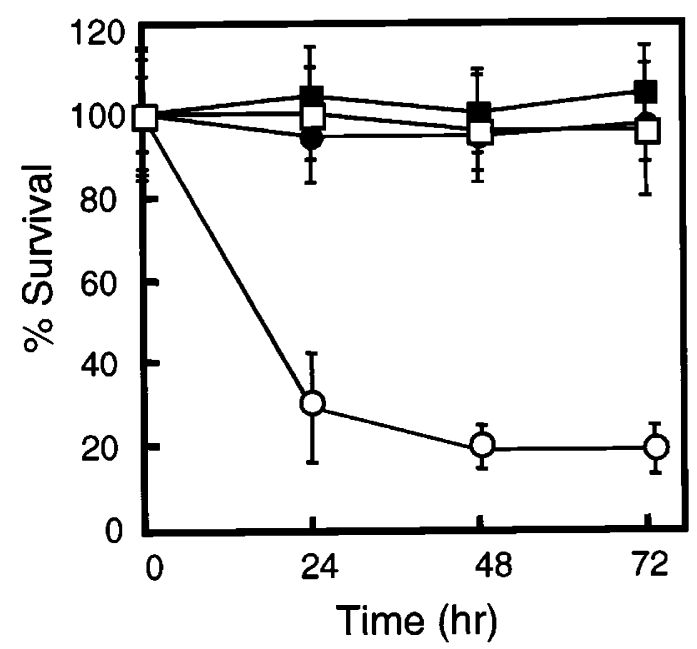

B

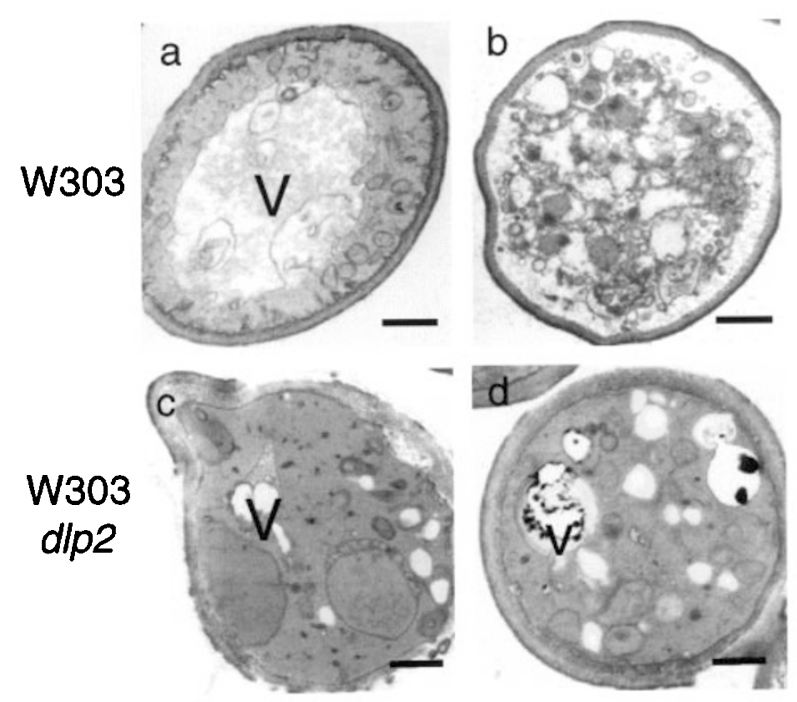

Figure 10 Effect of dlp2 mutation on Bax-induced cell death. (A) Cell viability of the wild-type W303 $(O, \square)$ and mutant W303/dlp2 $(\mathbf{\bullet}, \mathbf{\square})$, with (W303/bax and W303/dlp2/bax, $\mathrm{O}, \boldsymbol{\bullet})$ and without (W303 and W303/dlp2, $\square, \boldsymbol{\square})$ transformation with galactose-inducible Bax. Cells were transferred to galactose medium at time zero. These are representative patterns of two independent experiments assayed in triplicate. (B) Electron micrographs of representative W303/bax (a and b) and W303/dlp2/bax (c and d) cells after Bax induction on galactose medium. Photographs were taken $24 \mathrm{~h}$ after the Bax induction. V, vacuole. The bar represents $1 \mu \mathrm{m}$

either cultured in YPAD medium or in synthetic YNB medium which was prepared as described previously. ${ }^{14,37}$

\section{Mutagenesis of yeast cells with ethylmethane sulfonate (EMS) and isolation of dlp mutants}

The parental cdc28 cells were mutagenized with EMS as described elsewhere ${ }^{38}$ and dlp mutants were isolated as described previously. ${ }^{14}$
In brief, EMS-treated cells grown on agar plates containing YPAD at the permissive temperature $\left(25^{\circ} \mathrm{C}\right)$ were replica-plated and incubated at $38^{\circ} \mathrm{C}$ for 4 days and at $25^{\circ} \mathrm{C}$ for a further 3 days. Viable colonies were removed as candidate dlp mutants. Of these, revertants of the cdc28 mutant and apg mutants sensitive to nitrogen starvation ${ }^{34}$ were eliminated as described previously. ${ }^{14}$ Back-crossing of dlp candidates was repeated at least three times using STX326-8B (cdc28). We characterized one of the recessive mutant probably derived from a single gene, named dlp2.

\section{Isolation of a gene that complements the dlp2 mutant phenotype}

A genomic library constructed with the multicopy vector YEp13M4 was used for transformation of cdc28 dlp2, and revertants of dlp2 were selected that lost proliferative activity within 4 days after the temperature shift. Genes contained in the inserts were identified by partial sequencing performed using a DNA sequencer SQ-3000 (Hitachi, Japan) and by physical mapping with restriction enzymes. The five genes, ARL1, UBS1, TYR1, 167C and 168W, contained in common in the inserts were removed from pAB104 (see Figure 2), subcloned in YEp13M4 plasmid and transformed into cdc28 dlp2 cells as follows. ARL1, contained in the EcoRI-BamHI fragment, was inserted into the BamHI site of YEp13M4 after blunt-ending and the recombinant plasmid YEp13M4-ARL1 was transformed into cdc28 dlp2, obtaining cdc28 dlp2/YEp-ARL1 (Table 1). UBS1 and $T Y R 1$, carried in the Stul-Bglll and Stul-Stul fragments, respectively, were ligated into YEp13M4 digested with Smal and BamHI. The $167 \mathrm{C}$ and $168 \mathrm{~W}$ genes in the $1.5 \mathrm{~kb}$ and $0.7 \mathrm{~kb}$ Hindll fragments, respectively, were inserted into the Hindll site of the vector. The recombinant plasmids carrying UBS1, TYR1, 167C and $168 \mathrm{~W}$ were separately transformed into $c d c 28$ dlp2. Transformants were incubated at $38^{\circ} \mathrm{C}$ for 3 days and at $25^{\circ} \mathrm{C}$ for a further 3 days when tested for complementation of the Dlp phenotype. To insert $A R L 1$ into a centromere-based vector, pRS415, a Sacl-BamHI fragment from pAB104 was ligated into the vector digested with Sacl and BamHI. The resultant plasmid pRS415-ARL1 was transformed into dlp2, obtaining transformants named cdc28 dlp2/pRS-ARL1 (Table 1).

To replace the point mutation with the normal sequence of $A R L 1$, the $E c o R I-B a m H I$ fragment from pAB104 was inserted into pUC119 digested with EcoRI and BamHI. The resultant pUC119-ARL1 was digested with Sphl and Sacl to remove a Pstl site in pUC119, and the rest of the recombinant plasmid was ligated. A Bg/ll-Hindll fragment was removed from the recombinant plasmid, blunt-ended and ligated with a blunt-ended 1.6-kb HindllI-BamHI fragment containing LEU2 from pRS415 (Stratagene, La Jolla, CA, USA). The resultant plasmid was cut at the Pstl site and transformed into cdc28 dlp2 mutant cells obtaining transformants named cdc28 dlp2/ARL1 (Table 1). The integration of the fragment into the genomic $A R L 1$ locus was verified by determining the physical maps of the DNA fragments of the $A R L 1$ gene amplified by polymerase-chain reaction (PCR) using synthetic oligonucleotides 5'-ACTTAAAGCTTCTCCTCGCACAAAATCACG-3' as the 5'-primer and 5'-AATCTAAGCTTCTATAACTGTTCCTC-3' as the $3^{\prime}$-primer.

Yeast transformation was performed as previously described. ${ }^{39}$

\section{Formation of ARL1-deleted mutant (cdc28 arl1 $\Delta$ ) and transformation with arl1-1}

To form arl1 $\Delta$ of the parental cdc28 cell, $A R L 1$ in pUC119-ARL1 was disrupted at the Pstl site with the HindllI-BamHI fragment containing 
LEU2 from pRS415, and the 2.2-kb Pvull fragment from the resulting plasmid containing $A R L 1:: L E U 2$ was transformed into the parental cdc28 cells. The integration of the fragment into the genomic $A R L 1$ locus was verified as described above.

To transform cdc28 arl1 $\Delta$ with a recombinant plasmid harboring arl1-1, a 2.2-kb fragment containing arl1-1 and a 1.0-kb promoter region was PCR-amplified on genomic DNA from cdc28 dlp2 cells using synthetic oligonucleotides 5'-AAGTGAAGCTTTGAGCATTGTAAGAGGAC-3' as the $5^{\prime}$-primer and $5^{\prime}$-TTTCCAAAGCTTCATCTTCCCATATGATCC- $3^{\prime}$ as the $3^{\prime}$-primer, each containing a Hindlll site. The PCR-product was blunt-ended and inserted into an EcoRV site of pRSK103, which was constructed by inserting with the $B g / l-E c o R I$ fragment containing the kan gene from pFA6a ${ }^{40}$ between the Eco47III and Kpnl sites in pRS413. The resulting recombinant plasmid pRSK103-arl1-1 was transformed into cdc28 arl1A, and transformants, named cdc28 arl1 $/ \mathrm{pRS}-\operatorname{arl1-1}$ (Table 1), were selected on medium containing $1000 \mu \mathrm{g} / \mathrm{ml}$ Geneticin.

\section{Insertion of dlp2 mutation into the ARL1 locus of the wild-type W303 cells}

To insert the point mutation of arl1-1 in the ARL1 locus of W303, the Pstl-Narl fragment from pUC119-ARL1 was ligated with pUC119(LEU2) that had been digested with Pstl and Narl, and the resultant plasmid was transformed into W303 after linearization by Pstl digestion. Transformants were selected on agar containing synthetic medium lacking leucine, and named W303/dlp2 (Table 1). The presence of the point mutation in the ARL 1 locus was confirmed by sequencing the PCR product amplified using genomic DNA as template and the synthetic oligonucleotides described above as primers.

\section{Transformation of W303 and W303/dlp2 with bax}

The plasmid pYX223 was digested with Pstl, dephosphorylated and ligated with the Pstl-Pstl fragment from pUC119 (TRP1) so that TPR1 could be used as a selection marker. The plasmid thus obtained, pYX223(TRP1), was digested with EcoRl and Xhol and ligated with the EcoRI-Xhol fragment from pEG202-mbax containing murine bax, resulting in pYX223-bax, carrying bax under the control of the GAL1 promoter. pYX223-bax was transformed into W303 and W303/dlp2 cells obtaining W303/bax and W303/dlp2/bax, respectively (Table 1 ).

\section{Sequencing of ARL1 from dlp2 mutant cells}

ARL1 in the genomic DNA from cdc28 dlp2 mutant cells was PCRamplified using synthetic oligonucleotides 5 -TATAGGAATTCATGGGTAACATTTTTAG- $3^{\prime}$ as the $5^{\prime}$-primer and $5^{\prime}$-AATCTAAGCTTCTATAACTGTTCCTC- $3^{\prime}$ as the $3^{\prime}$-primer, and the PCR product was sequenced.

\section{Morphological observation by light and electron microscopy}

Cells were examined morphologically as described previously. ${ }^{13}$ Vital staining of vacuoles with the fluorescent dye Lucifer yellow $\mathrm{CH}$ (Sigma) was performed as described elsewhere. ${ }^{17}$ To follow membrane transport to vacuole, cells were stained with a lipophilic styryl dye, $\mathrm{N}$ (3-triethylammoniumpropyl)-4-( $p$-diethylaminophenyl-hexatrienyl) pyridinium dibromide (FM4-64). ${ }^{23}$ Cells suspended at $4 \mathrm{OD}_{600} \mathrm{U} / \mathrm{ml}$ were added with FM4-64 at $4 \mu \mathrm{M}$, which is one-tenth the concentration used by Vida and $\mathrm{Emr},{ }^{24}$ and incubated at $30^{\circ} \mathrm{C}$ for $30-120 \mathrm{~min}$.

\section{Determination of cell viability by measuring colony-forming activity}

Yeast cells were cultured to stationary phase $\left(>1 \times 10^{8}\right.$ cells $\left./ \mathrm{ml}\right)$ in YPAD medium at $25^{\circ} \mathrm{C}$, and virgin cells were prepared according to the method of Egilmez et al. ${ }^{41}$ For the determination of colony-forming activity, a known number of cells was plated and cultured on YPAD agar plates at $25^{\circ} \mathrm{C}$. Colonies were counted after 2 days.

Survival rate after nitrogen starvation was determined as described elsewhere. $^{42}$

\section{Western blotting}

Western blotting of carboxypeptidase $Y(C P Y)$ and alkaline phosphatase (ALP) was performed as described previously ${ }^{43}$ using anti-CPY and anti-ALP antibodies (Molecular Probes, Eugene, OR, USA).

\section{References}

1. Zha H, Fisk HA, Yaffe MP, Mahajan N, Herman B and Reed JC (1996) Structurefunction comparisons of the proapoptotic protein bax in yeast and mammalian cells. Mol. Cell. Biol. 16: 6494-6508

2. Mannon S, Chaudhuri B and Guerin M (1997) Release of cytochrome $c$ and decrease of cytochrome c oxidase in Bax-expressing yeast cells, and prevention of these effects by coexpression of Bcl-XL. FEBS Lett. 415: 29-32

3. Tao W, KurschnerC and Morgan JI (1997) Modulation of cell death in yeast by the Bcl-2 family of proteins. J. Biol. Chem. 272: 15547-15552

4. Jürgensmeier JM, KrajewskiS, Armstrong RC, Wilson GM, Oltersdorf T, Fritz LC, Reed JC and Ottilie S (1997) Bax- and Bak-induced cell death in the fission yeast Schizosaccharomyces pombe. Mol. Biol. Cell. 8: 325-339

5. Ligr M, Madeo F, Frölich E, HiltW, Frölich KU and WolfDH (1998) Mammalian bax triggers apoptotic changes in yeast. FEBS Lett. 438: 61-65

6. Schweichel JU and Merker HJ (1973) The morphology of various types of cell death in prenatal tissues. Teratology 7: 253-266

7. Clarke PGH (1990) Developmental cell death: morphological diversity and multiple mechanisms. Anat. Embryol. 181: 195-213

8. Zakeri Z, Bursch W, Tenniswood M and Lockson RA (1995) Cell death: programmed, apoptosis, necrosis, or other? Cell. Death Differ. 2: 87-96

9. Chi S, Kitanaka C, Noguchi K, Mochizuki T, Nagashima Y, Shirouzu M, Fujita H, Yoshida M, Chen W, Asai A, Himeno M, Yokoyama S and Kuchino Y (1999) Oncogenic Ras triggers cell suicide through the activation of a caspaseindependent cell death program in human cancer cells. Oncogene 18: 22812290

10. Xiang J, Chao DT and Korsmeyer SJ (1996) BAX-induced cell death may not require interleukin $1 B$-converting enzyme-like proteases. Proc. Natl. Acad. Sci. USA 93: $14559-14563$

11. Madeo F, Frölich E and Frölich KW (1997) A yeast mutant showing diagnostic markers of early and late apoptosis. J. Cell. Biol. 139: 729-734

12. Madeo F, Frölich E, Ligr M, Grey M, Sigrist SJ, Wolf DH and Frölich KW (1997) Oxygen stress: a regulator of apoptosis in yeast. J. Cell. Biol. 145: 757-767

13. Motizuki M, Yokota S and Tsurugi K (1995) Autophagic death after cell cycle arrest at the restrictive temperature in temperature-sensitive cell division cycle and secretory mutants of the yeast Saccharomyces cerevisiae. Eur. J. Cell. Biol. 68: $275-287$

14. Xu Z, Mitsui K, Motizuki M, Yaguchi S and Tsurugi K (1999) The DLP1 mutant of the yeast Saccharomyces cerevisiae with an increased copy number of the $2 \mu$ plasmid shows a shortened lifespan. Mech. Ageing Dev. 110: 119-129

15. Sinclair DA and Guarente L (1997) Extrachromosomal rDNA circles - A cause of aging in yeast. Cell 91: 1033-1042

16. Takeshige K, Baba M, Tsuboi S, Noda T and Ohsumi Y (1992) Autophagy in yeast demonstrated with proteinase-deficient mutants and conditions for its induction. J. Cell. Biol. 119: 301-311

17. Riezman $\mathrm{H}$ (1985) Endocytosis in yeast: Several of the yeast secretory mutants are defective in endocytosis. Cell 40: 1001-1009 
18. Lee FJS, Huang CF, Yu WL, Buu LM, Lin CY, Huang MC, Moss J and Vaughan M (1997) Characterization of an ADP-ribosylation factor-like 1 protein in Saccharomyces cerevisiae. J. Biol. Chem. 272: 30998-31005

19. Herskowitz I (1987) Functional inactivation of genes by dominant negative mutations. Nature 329: 219-222

20. Stevens TH, Rothman JH, Payne GS and Schekman R (1986) Gene dosagedependent secretion of yeast vacuolar carboxypeptidase Y. J. Cell. Biol. 102: $1551-1557$

21. Klinosky DJ and Emr SD (1989) Membrane protein sorting: biosynthesis transport and processing of yeast vacuolar alkaline phosphatase. EMBO J. 8: 2241-2250

22. Raymond CK, Howald-Stevenson I, Vater CA and Stevens TH (1992) Morphological classification of the yeast vacuolar protein sorting mutants: evidence for a prevacuolar compartment in class Evsp mutants. Mol. Biol. Cell. 3 : $1389-1402$

23. Vida TA, Huyer G and Emr SD (1993) Yeast vacuolar proenzymes are sorted in the late Golgi complex and transported to the vacuole via a prevacuolar endosome-like compartment. J. Cell. Biol. 121: 1245-1256

24. Vida TA and Emr SD (1995) A new vital stain for visualizing vacuolar membrane dynamics and endocytosis in yeast. J. Cell. Biol. 128: 779-792

25. Moss J and Vaughan M (1995) Structure and function of ARF proteins: Activators of cholera toxin and critical components of intracellular vesicular transport processes. J. Biol. Chem. 270: 12327-12330

26. Boman AL and Kahn RA (1995) Arf proteins: the membrane traffic police? Trends Biol. Sci. 20: 147-150

27. Huang CF, Buu LM, Yu WL and Lee FJS (1999) Characterization of a novel ADP ribosylation factor-like protein (yARL3) in Saccharomyces cerevisiae. J. Biol. Chem. 274: 3819-3827

28. Gaynor EC, Chen CY, Emr SD and Graham TR (1998) ARF is required for maintenance of yeast Golgiand endosome structure and function. Mol. Biol. Cell. 9: $653-670$

29. Poon PP, Cassel D, Spang A, Rotman M, Pick E, Singer RA and Johnston GC (1999) Retrograde transport from the yeast Golgi is mediated by two ARF GAP proteins with overlapping function. EMBO. J. 18: 555-564

30. Blader IJ, Jamie M, Cope TV, Jackson TR, Profit AA, Greenwood AF, Drubin DG, Prestwich GD and Theibert AB (1999) GCS1, an Arf guanosine triphosphataseactivating protein in Saccharomyces cerevisiae, is required for normal actin cytoskelton organization in vitro and stimulates actin polymerization in vitro. Mol. Biol. Cell. 10: 581-596
31. Hoyt MA, Stearns T and Botstein D (1990) Chromosome instability mutants of Saccharomyces cerevisiae that are defective in microtubule-mediated processes. Mol. Cell. Biol. 10: 223-234

32. Bhamidipati A, Lewis SA and Cowan NJ (2000) ADP ribosylation factor-like protein 2 (Arl2) regulates the interaction of tubulin-folding cofactor $D$ with native tubulin. J. Cell. Biol. 149: 1087-1096

33. Lane J and Allan V (1998) Microtubule-based membrane movement. Biochim. Biophys. Acta. 1376: $27-55$

34. Tsukada M and Ohsumi $Y$ (1993) Isolation and characterization of autophagydefective mutants of Saccharomyces cerevisiae. FEBS Lett. 333: 169-174

35. Mizushima N, Noda T, Yoshimori T, Tanaka Y, Ishii T, George MD, Klionsky DJ, Ohsumi M and Ohsumi Y (1998) A protein conjugation system essential for autophagy. Nature 395: 395-398

36. Kamada Y, Funakoshi T, Shintani T, Nagano K, Ohsumi M and Ohsumi Y (2000) Tor-mediated induction of autophagy via an Apg1 protein kinase complex. J. Cell. Biol. 150: 1507-1513

37. Kawabata K, Mitsui K, Uno T, Tamura Kand TsurugiK(1999)Protein interactions of Gts $1 p$ of Saccharomyces cerevisiae throughout a region similar to a cytoplasmic portion of some ATP-binding cassette transporters. Eur. J. Biochem. 259: 112-119

38. Spencer JFT and Spencer DM (1988) Yeast genetics. In Yeast, a Practical Approach, Campbell I, Duffus JH eds (London: IRL Press) pp. 65-106

39. Hill J, Donald KA, Griffiths DE and Donald G (1991) DMSO-enhanced whole cell yeast transformation. Nucl. Acids Res. 19: 5791

40. Wach A, Brachat A, Alberti-Segui C, Rebischung C and Philippsen P (1997) Heterologous HIS3 marker and GFP reporter molecules for PCR-targeting in Saccharomyces cerevisiae. Yeast 13: 1065-1075

41. Egilmez NK, Chen JB and Jazwinski SM (1990) Preparation and partial characterization of old yeast cells. J. Gerontol. 45: B9-B17

42. Scott SV, Hefner-Gravink A, Morano KA, Noda T, Ohsumi Y and Klionsky DJ (1996) Cytoplasm-to-vacuole targeting and autophagy employ the same machinery to deliver proteins to the yeast vacuole. Proc. Natl. Acad. Sci. USA 93: $12304-12308$

43. Mitsui K, Yaguchi S and Tsurugi K (1994) The GTS1 gene, which contains a GlyThr repeats, affects the timing of budding and cell size of the yeast Saccharomyces cerevisiae. Mol. Cell. Biol. 14: 5569-5578 